\title{
Prostaglandins Facilitate Peptide Release from Rat Sensory Neurons by Activating the Adenosine $3^{\prime}, 5^{\prime}$-Cyclic Monophosphate Transduction Cascade
}

\author{
Cynthia M. Hingtgen, ${ }^{1}$ Kenneth J. Waite, ${ }^{1}$ and Michael R. Vasko ${ }^{1,2}$ \\ 'Department of Pharmacology and Toxicology and '2Department of Anesthesia, Indiana University School of \\ Medicine, Indianapolis, Indiana 46202-5120
}

\begin{abstract}
Prostaglandins sensitize sensory neurons to activation by mechanical, thermal and chemical stimuli. This sensitization also results in an increase in the stimulus-evoked release of the neuroactive peptides, substance $P$ and calcitonin gene-related peptide from sensory neurons. The cellular transduction cascade underlying the prostaglandininduced augmentation of peptide release is not known. Therefore, we examined whether the sensitizing action of prostaglandins on peptide release from sensory neurons grown in culture is mediated by the second messenger, adenosine $3^{\prime}, 5^{\prime}$ cyclic monophosphate (cAMP). Prostaglandin $E_{2}$ and carba prostacyclin (a stable analog of prostaglandin $\mathrm{I}_{2}$ ) significantly increase the content of CAMP-like immunoreactive substance (icAMP) in the sensory neuron cultures at concentrations that also augment the bradykinin- or capsaicin-evoked release of peptides. Furthermore, pretreating sensory neurons with agents that increase intracellular CAMP mimics the sensitizing action of prostaglandins. Exposing cultures to either forskolin (0.1-10 $\mu \mathrm{m})$, cholera toxin $(1.5 \mu \mathrm{g})$, or 8-bromo-cAMP $(100 \mu \mathrm{M})$ results in a significant enhancement of the bradykinin- or capsaicin-stimulated release of both substance P-like and calcitonin gene-related peptide-like immunoreactive substances. Pretreating sensory neurons with the adenylyl cyclase inhibitor, 9-tetrahydro-2-furyl adenine $(5 \mathrm{~mm})$, abolishes the prostaglandin-induced increases in icAMP content and attenuates the prostaglandin $E_{2}$ or carba prostacyclin enhancement of the evoked release of calcitonin gene-related peptide-like immunoreactive substance. These results demonstrate that the cAMP transduction cascade mediates the sensitizing actions of prostaglandins on peptide release from sensory neurons.
\end{abstract}

[Key words: adenylyl cyclase, cAMP, calcitonin gene-related peptide, dorsal root ganglia, prostaglandins, sensory neurons, substance $P$ ]

Increasing evidence suggests that selective prostaglandins have a direct action on sensory neurons to enhance the release of neuroactive peptides, substance P (SP), and calcitonin gene-re-

\footnotetext{
Received Dec. 20, 1994; revised Mar. 7, 1995; accepted Mar. 14, 1995.

This work was supported by PHS 1-P60 AR20582-15 to M.R.V. and the Showalter Research Trust. C.M.H. is a combined-degree fellow at Indiana University School of Medicine. We thank Dr. Grant Nicol for his advice and extensive discussions regarding this wotk.

Correspondence should be addressed to Michael R. Vasko, Ph.D., Department of Pharmacology and Toxicology, Indiana University School of Medicine, 635 Barnhill Drive, Indianapolis, IN 462024120.

Copyright @ 1995 Society for Neuroscience 0270-6474/95/155411-09\$05.00/0
}

lated peptide (CGRP). Indeed, micromolar concentrations of $\mathrm{PGE}_{2}$ or $\mathrm{PGI}_{2}$ increase peptide release from peripheral tissues (Franco-Cereceda, 1989; Geppetti et al., 1991), from spinal cord slices (Andreeva and Rang, 1993; Vasko et al., 1993), and from isolated sensory neurons (Nicol et al., 1992; Vasko et al., 1993). Recent studies in our laboratory have shown that nanomolar concentrations of $\mathrm{PGE}_{2}$ or $\mathrm{PGI}_{2}$ sensitize rat sensory neurons grown in culture, thereby augmenting the release of SP and CGRP evoked by the algogenic agents, capsaicin or bradykinin, without altering resting release (Hingtgen and Vasko, 1994a; Vasko et al., 1994). This effect of prostaglandins on peptide release is analogous to the sensitizing actions of these autocoids using other experimental end points. For example, pretreating sensory nerve preparations with $\mathrm{PGE}_{2}$ or $\mathrm{PGI}_{2}$ increases the number of action potentials elicited in response to thermal, mechanical, or chemical stimuli (Handwerker, 1976; Mense, 1981; Baccaglini and Hogan, 1983; Martin et al., 1987; Schaible and Schmidt, 1988; Cui and Nicol, 1994). These prostanoids also reduce the intensity of noxious stimuli needed to elicit various escape behaviors in laboratory animals (Ferreira et al., 1978; Taiwo et al., 1987), and they enhance pain perception in man (Ferreira, 1972). Because the release of SP and CGRP from sensory neurons is a critical event in modulating pain perception and in initiating neurogenic inflammation (Cuello, 1987; Kuraishi et al., 1988; Payan, 1989), it is interesting to speculate that prostaglandin-induced hyperalgesia may result from an action of these autocoids on peptide release.

Although $\mathrm{PGE}_{2}$ and $\mathrm{PGI}_{2}$ can sensitize sensory neurons, enhancing excitability and peptide release, the signal transduction cascade mediating these actions has not been elucidated. We therefore performed experiments to test the hypothesis that the sensitizing actions of prostaglandins on peptide release are mediated by activation of the cAMP transduction cascade. This hypothesis is based in part on indirect evidence suggesting that the hyperalgesic actions of prostaglandins are mediated by cAMP (Ferreira and Nakamura, 1979; Taiwo et al., 1989; Taiwo and Levine, 1991). Furthermore, in non-neuronal cells, the binding of $\mathrm{PGI}_{2}$ or $\mathrm{PGE}_{2}$ to specific prostanoid receptors can result in activation of the cAMP transduction cascade (Smith et al., 1987; Jaschonek et al.; 1988; Namba et al., 1993). Because the transduction cascade for various prostaglandins is tissue specific, it is necessary to establish cause-effect relationships between prostaglandin actions on sensory neurons and changes in cAMP to determine if prostaglandin-induced sensitization of sensory neurons is mediated hy this second messenger.

To establish if the sensitizing action of prostaglandins on pep- 
tide release is mediated by activation of the cAMP transduction cascade, we studied the effects of manipulating this second messenger on the evoked release of SP-like and CGRP-like immunoreactive substances (iSP; iCGRP) from rat sensory neurons in culture. We also examined the effects of inhibiting cAMP production in sensory neurons on the ability of prostaglandins to augment peptide release evoked by capsaicin or bradykinin.

Our results demonstrate that pretreating sensory neurons in culture with agents that increase intracellular cAMP enhances the release of peptides evoked by either bradykinin or capsaicin in a manner analogous to $\mathrm{PGE}_{2}$ or $\mathrm{PGI}_{2}$. Furthermore, preventing the prostaglandin-induced increase in intracellular cAMP attenuates the sensitizing actions of these prostanoids on the evoked release of iCGRP.

Preliminary findings from these studies have appeared in abstract form (Hingtgen and Vasko, 1992; Waite and Vasko, 1992).

\section{Materials and Methods}

Materials. Timed-pregnant Sprague-Dawley rats were obtained from Harlan-Sprague Dawley, Inc. (Indianapolis, IN). Cell culture supplies were purchased from GIBCO BRL (Grand Island, NY), and nerve growth factor from Harlan Bioproducts for Science, Inc. (Indianapolis, IN). Peptides were obtained from Peninsula Laboratory (Belmont, CA), prostaglandins from Caymen Chemical Co. (Ann Arbor, MI), and all other chemicals from Sigma Chemical Co. (St. Louis, MO). The adenylyl cyclase inhibitor, 9-(tetrahydro-2-furyl)adenine, was a generous gift from G. Nicol (Indiana University School of Medicine), who obtained the compound on request from Squibb Industrics (Princeton, NJ). Prostaglandins, capsaicin, and forskolin were initially dissolved in 1-methyl-2-pyrrolidinone (HPLC grade, Aldrich Chemical Company, Milwaukee, WI) and then diluted to appropriate concentrations with HEPES buffer. This vehicle did not alter the release of either peptide at the concentrations used.

Isolation and culture of embryonic rat sensory neurons. The procedure for isolating and growing sensory neurons has been described previously (Hingtgen and Vasko, 1994a; Vasko et al., 1994). The sensory neurons were dissociated from the dorsal root ganglia of E15-E17 rat embryos using $0.025 \%$ trypsin (type IX) and mechanical agitation. Approximately 150,000 cells were plated into collagen-coated wells of a 24-well Falcon culture dish and grown in Dulbecco's Modified Eagle Medium supplemented with $2 \mathrm{~mm}$ glutamine, $50 \mu \mathrm{g} / \mathrm{ml}$ penicillin and streptomycin, $10 \%(\mathrm{v} / \mathrm{v})$ heat-inactivated fetal bovine scrum, $50 \mu \mathrm{M}$ 5-fluoro-2'-deoxyuridine, $150 \mu \mathrm{M}$ uridine, and $250 \mathrm{ng} / \mathrm{ml}$ nerve growth factor. Cultures were maintained at $37^{\circ} \mathrm{C}$ in a $5 \% \mathrm{CO}_{2}, 95 \%$ air atmosphere. The medium was changed every second day.

Release of iSP and iCGRP from sensory neurons. After 9-12 d in culture, release studies were performed on the cells as previously described (Hingtgen and Vasko, 1994a; Vasko et al,, 1994). Briefly, the neuronal cultures were washed once with HEPES buffer consisting of (in mM) $25 \mathrm{HEPES}, 135 \mathrm{NaCl}, 3.5 \mathrm{KCl}, 2.5 \mathrm{CaCl}_{2}, 1 \mathrm{MgCl}_{2}, 3.3 \mathrm{D}$-glucose, 0.1 ascorbic acid, 0.02 bacitracin, 0.001 phosphorhimadon, and $0.1 \%$ bovine serum albumin, $\mathrm{pH} 7.4$ and maintained at $37^{\circ} \mathrm{C}$, then incubated for successive 10 min intervals with $0.4 \mathrm{ml}$ of the same buffer in the absence or presence of drugs. Basal or resting release was determined by exposing the cells to HEPES buffer alone, or buffer in the presence of prostaglandins, forskolin, 8-bromo adcnosinc 3', 5'-cyclic monophosphate (8-bromo cAMP), cholera toxin, or 9-tetrahydro-2-furyl adenine (THFA). To determine evoked release, the initial incubation was followed by a $10 \mathrm{~min}$ incubation with the same concentration of a drug in the presence of $50 \mathrm{~nm}$ capsaicin or $100 \mathrm{~nm}$ bradykinin. We have previously demonstrated that these concentrations of capsaicin and bradykinin cause submaximal stimulation of peptide release (Hingtgen and Vasko, 1994a; Vasko et al., 1994). Consequently, the use of these concentrations optimized the possibility of observing an enhancement or inhibition of evoked release by prostaglandins or agents that alter intracellular cAMP. After exposure to the stimulus, cells were reexposed to HEPES buffer without drugs for one or two $10 \mathrm{~min}$ incubations to reestablish resting release. During incubations, the cells were maintained in a $5 \% \mathrm{CO}_{2}$ environment at $37^{\circ} \mathrm{C}$. When the cells were pretreated with 8-bromo cAMP, THFA, or cholera toxin, the drug was added to the culture medium for the designated pretreatment time, and then the cells were initially incubated in HEPES buffer containing the same concentration of the agent to determine if the drug altered basal release.

After each incubation, the buffer was removed to measure the amount of both iSP and iCGRP using radioimmunoassays (RIAs) as previously described (Vasko et al., 1993, 1994). The antiserum for iSP was raised in our laboratory (Pang and Vasko, 1986), whereas the iCGRP antiserum was a generous gift from Dr. M. Iadarola (NIH). At the highest concentrations utilized, none of the drugs used in these studies except THFA altered the RIAs for either peptide. THFA $(5 \mathrm{~mm})$ caused some interference with the iSP assay but did not affect the RIA for iCGRP. Consequently, iSP release was not measured in experiments involving THFA.

Determination of icAMP content in sensory neuronal cultures. The content of cAMP-like immunoreactive substance (icAMP) was measured from cells after 9-12 d in culture. Growth medium was aspirated from the culture dish and cells were washed with $0.5 \mathrm{ml}$ of HEPES buffer containing $2 \mathrm{~mm} 3$-isobutyl-1-methyl-xanthine (IBMX, a phosphodiesterase inhibitor). After washing, cells were incubated in $0.5 \mathrm{ml}$ HEPES containing IBMX for $20-30$ min in the absence or presence of other drugs. In the absence of IBMX, tissue content of icAMP under control conditions was at or near the limit of delectability of the radioimmunoassay. Consequently, IBMX was used in all experiments to enhance the content of cAMP in the cultures and thus allow statistical comparison of "basal" levels of the nucleotide with the effects of prostaglandins and forskolin. The HEPES buffer was aspirated and the cells were exposed to $100 \mathrm{~mm} \mathrm{HCl}$. The cells were scraped into the acid solution and these samples were removed, boiled for $5 \mathrm{~min}$, and centrifuged at $1200 \times \mathrm{g}$ for $15 \mathrm{~min}$. The supernatant was frozen and lyophilized. Samples were resuspended and assayed with a cAMP assay kit (NEN Products, DuPont Co., Wilmington, DE) using the nonacetylated protocol.

Statistical analysis. Unless otherwise stated, data is presented as the mean \pm standard error of the mean (SEM) of wells from at least three separate experiments. To compare the effects of various concentrations of one drug or the effects of drug combinations, an overall test based on the analysis of variance was performed. If this test indicated that a difference existed, post hoc tests were performed. To compare the effect of different concentrations of one compound to basal or vehicle levels, a Fisher's LSD test was performed. To compare several different treatments, a Bonferroni-Dunn all means test was used. The significance level for all tests was set at 0.05 .

\section{Results}

\section{Selected prostaglandins increase the content of icAMP in} sensory neuronal cultures

As a first step in establishing that cAMP is involved in the sensitizing actions of prostaglandins on peptide release, we determined whether $\mathrm{PGE}_{2}$ or $\mathrm{CPGI}_{2}$ could elevate the content of icAMP in the cultures. This was accomplished by exposing sensory neurons to various concentrations of these prostanoids for 20-30 min in the presence of IBMX and directly measuring cyclic nucleotide content. When sensory neurons were incubated for 20 min with HEPES buffer containing 2 mM IBMX, the basal levels of icAMP were $4.8 \pm 0.3 \mathrm{pmol} / \mathrm{well}$ and $5.8 \pm 1.0 \mathrm{pmol} /$ well (open columns Fig. 1A). Exposing the neurons to $10 \mathrm{~nm}$ $\mathrm{PGE}_{2}$ did not increase icAMP content. In contrast, both $100 \mathrm{nM}$ and $1 \mu \mathrm{M} \mathrm{PGE}{ }_{2}$ caused a significant increase in icAMP levels to $10.1 \pm 1.1 \mathrm{pmol} / \mathrm{well}$ and $12.6 \pm 1.0 \mathrm{pmol} / \mathrm{well}(n=24)$, respectively (Fig. $1 \Lambda$ ). In a similar manner, treating the neuronal cultures for 30 min with various concentrations of $\mathrm{CPGI}_{2}$ resulted in a significant increase in icAMP content compared to cultures treated with $2 \mathrm{mM}$ IBMX alone. Both $1 \mathrm{nM}$ and $10 \mathrm{~nm}$ $\mathrm{CPGI}_{2}$ elevated icAMP levels approximately twofold compared to basal levels, whereas higher concentrations (100 $\mathrm{nM}$ or $1 \mu \mathrm{M})$ increased content of the cyclic nucleotide by five- to sixfold (Fig. 1A). The observation that 100 nM $\mathrm{PGE}_{2}, 1 \mu \mathrm{M} \mathrm{PGE}_{2}$, or 1 $\mathrm{nM} \mathrm{CPGI} \mathrm{C}_{2}$ causes a twofold increase in icAMP content is particularly interesting because these concentrations of prostanoids enhance the stimulus-evoked release of iSP and iCGRP without 
A

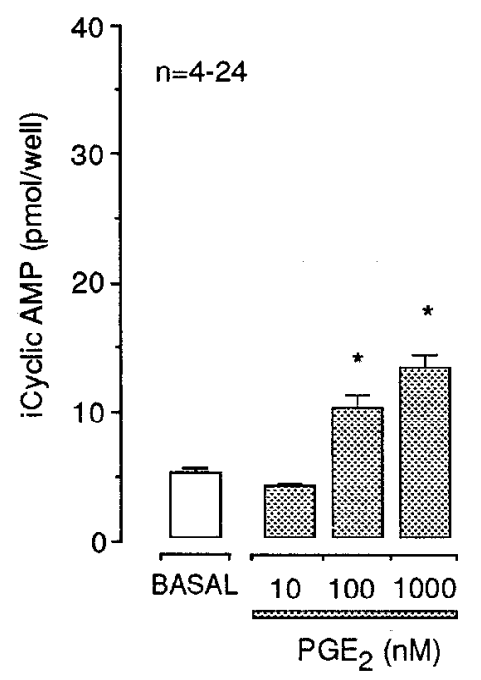

B

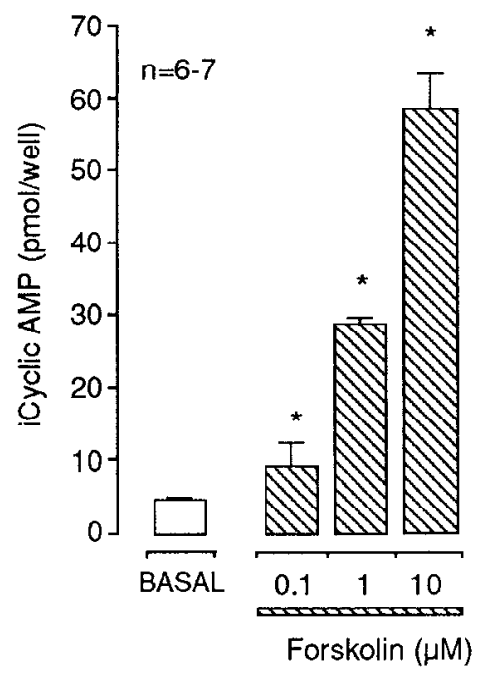

Figure 1 . Content of icAMP in sensory neuronal cultures is increased after exposure to $\mathrm{PGE}_{2}, \mathrm{CPGI}_{2}$, or forskolin. The columns represent the mean \pm SEM of the amount of icAMP extracted from individual sensory neuron cultures in pmol/well. A, The open column shows icAMP formed when cells are exposed to HEPES buffer containing 2 mM IBMX without prostanoid treatment (BASAL). The shaded columns represent cells treated with buffer containing IBMX and various concentrations of $\mathrm{PGE}_{2}$ for $20 \mathrm{~min}$ or various concentrations of CPGI for $30 \mathrm{~min}$. B, The open column shows cAMP formed when cultures are exposed to HEPES buffer containing 2 mM IBMX in the absence of forskolin (BASAL), whereas the hatched column represents icAMP content when cells were exposed to buffer containing IBMX and various concentrations forskolin for 20 min. An asterisk indicates significant differences from controls determined by analysis of variance and Bonferroni-Dunn all means test $(p<0.05)$.

altering resting release (Hingtgen and Vasko, 1994a; Vasko et al., 1994).

As a potential negative control, we examined the effects of prostaglandin $\mathrm{F}_{2 \alpha}\left(\mathrm{PGF}_{2 \alpha}\right)$ on icAMP content. We chose this prostanoid, because we have previously demonstrated that $1 \mu \mathrm{M}$ $\mathrm{PGF}_{2 \alpha}$ does not alter the resting or stimulus-evoked release of iSP or iCGRP (Hingtgen and Vasko, 1994a; Vasko et al., 1994).

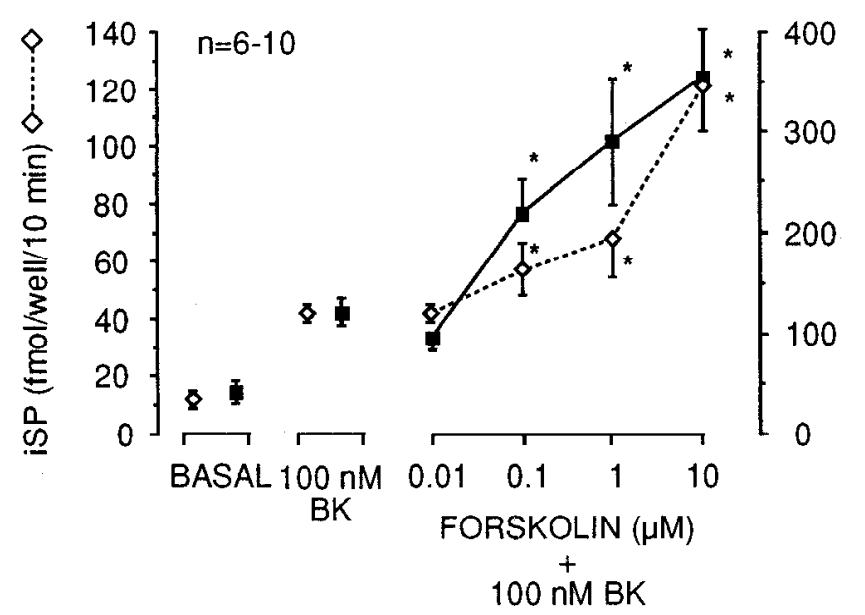

Figure 2. Forskolin augments bradykinin-stimulated release of iSP and iCGRP from rat sensory neurons. The ordinate represents the amount of iSP (open diamonds) and iCGRP (filled squares) release in cells exposed to HEPES buffer in the absence of bradykinin (BASAL) and release evoked by $100 \mathrm{~nm}$ bradykinin $(B K)$ in the absence and presence of forskolin, expressed in $\mathrm{fmol} / \mathrm{well} / 10 \mathrm{~min}$ incubation period. Values are the mean \pm SEM of the amount of peptide released in 610 wells. Cells were treated with forskolin 20 min prior to and throughout the bradykinin stimulation. An asterisk indicates statistically significant difference between release caused by bradykinin alone and by bradykinin in the presence of forskolin as determined by an analysis of variance and Fisher's LSD $(p<0.05)$.
Exposing neuronal cultures to this prostanoid for $30 \mathrm{~min}$ at concentrations of $100 \mathrm{nM}$ and $1 \mu \mathrm{M}$ did not significantly increase the content of icAMP compared to untreated controls. The levels of icAMP in cultures treated with $100 \mathrm{nM}$ or $1 \mu \mathrm{M} \mathrm{PGF}_{2 \alpha}$ were $5.0 \pm 0.4(n=4)$ and $8.0 \pm 1.0(n=7) \mathrm{pmol} / \mathrm{well}$, respectively.

Agents that increase cAMP levels enhance stimulus-evoked peptide release

To further investigate the role of cAMP in facilitation of peptide release, we tested whether elevating intracellular cAMP alters the resting or evoked release of iSP and iCGRP from isolated sensory neurons. To increase intracellular cAMP, culturcs wcre pretreated with either forskolin, 8-bromo cAMP, or cholera toxin, then resting and evoked release of peptides was determined. When neurons in culture were exposed for $20 \mathrm{~min}$ to $0.1,1$, or $10 \mu \mathrm{M}$ forskolin in the presence of $2 \mathrm{mM}$ IBMX, there was a significant increase in icAMP content compared to cells treated with IBMX alone (Fig. 1B). This increase was concentration dependent in that the lowest concentration of forskolin tested increased icAMP levels approximately twofold from a basal value of $4.7 \pm 0.3$ to $9.4 \pm 3.1 \mathrm{pmol} /$ well $(n-7)$, whereas $1 \mu \mathrm{M}$ and $10 \mu \mathrm{M}$ forskolin elevated icAMP levels to $28.6 \pm 0.9 \mathrm{pmol} /$ well $(n=6)$ and $58.5 \pm 5.0 \mathrm{pmol} /$ well $(n=6)$, respectively (Fig. $1 B$ ).

We next examined whether pretreating sensory neurons with forskolin would alter either the resting or evoked release of iSP or iCGRP. Sensory neurons in culture were exposed to various concentrations of forskolin for 20 min prior to and throughoul a 10 min incubation with $100 \mathrm{nM}$ bradykinin. In the absence of forskolin, the bradykinin-evoked release of iSP and iCGRP was $42 \pm 3 \mathrm{fmol} / \mathrm{well} / 10 \mathrm{~min}$ and $134 \pm 14 \mathrm{fmol} / \mathrm{well} / 10 \mathrm{~min}$, respectively (Fig. 2); a significant increase over basal release levels. The lowest concentration of forskolin tested (10 nM) did 
not enhance the bradykinin-stimulated release of either iSP or iCGRP (Fig. 2). However, at concentrations of $100 \mathrm{nM}$ to 10 $\mu \mathrm{M}$, forskolin pretreatment significantly augmented the bradykinin-evoked release of both iSP and iCGRP. Exposing the neurons to $100 \mathrm{~nm}$ forskolin increased the bradykinin-evoked peptide release approximately 1.5 -fold. Treating sensory neurons with $1 \mu \mathrm{M}$ forskolin caused a 1.6-fold enhancement of iSP release to a value of $68 \pm 13 \mathrm{fmol} / \mathrm{well} / 10 \mathrm{~min}$ and a twofold augmentation of iCGRP release to a value of $278 \pm 63 \mathrm{fmol} /$ well/10 min compared to neurons exposed to $100 \mathrm{nM}$ bradykinin alone (Fig. 2). In a similar manner, $10 \mu \mathrm{M}$ forskolin increased bradykinin evoked release of iSP and iCGRP to $121 \pm 16$ and $342 \pm 46 \mathrm{fmol} /$ well/ $10 \mathrm{~min}$, respectively. In contrast to its effects on evoked release, treating cultures with forskolin alone $(0.01-10 \mu \mathrm{M})$ had no effect on basal release of either peptide (data not shown).

When neuronal cultures were exposed to $50 \mathrm{~nm}$ capsaicin, an agent that selectively activates small diameter sensory neurons (Holzer, 1991), there was a four- to fivefold increase in the release of both iSP and iCGRP above basal levels (Fig. 3, left panels). Pretreating sensory neurons with $1 \mu \mathrm{M}$ forskolin (a concentration that had no effect on resting peptide release; hatched columns) significantly enhanced the capsaicin-stimulated release of both peptides compared to cells exposed to capsaicin alone. Release of iSP evoked by capsaicin alone was $32 \pm 9 \mathrm{fmol} /$ well/10 $\mathrm{min}$ ( $n=10$ wells), whereas iCGRP release was 206 $\pm 14 \mathrm{fmol} / \mathrm{well} / 10 \mathrm{~min}$ ( $n=9$ wells). After forskolin, the capsaicin-evoked release of iSP was increased eightfold to a value of $251 \pm 34 \mathrm{fmol} / \mathrm{well} / 10 \mathrm{~min}$, and the release of iCGRP was augmented sevenfold to $1355 \pm 258 \mathrm{fmol} /$ well $/ 10 \mathrm{~min}$. Peptide release also was significantly elevated in the $10 \mathrm{~min}$ interval after exposure to capsaicin, but returned to resting levels in the subsequent 10 min incubation (data not shown). The increase in release during the $10 \mathrm{~min}$ after capsaicin exposure occurred in both control cells (left panels, Fig. 3) and forskolin-treated cells (right panel, Fig. 3), suggesting that the effect was secondary to capsaicin treatment and not because of an elevation in cAMP.

One limitation of the studies using forskolin is that this agent may have actions that are not specifically mediated by an increase in adenylyl cyclase activity (Laurenza et al., 1989). Consequently, we exposed sensory neurons to either 8-bromo cAMP or cholera toxin to elevate intracellular levels of cAMP and determined the effects on resting and bradykinin-evoked peptide release. Treating the sensory neurons with $100 \mu \mathrm{M}$ 8-bromo cAMP (a membrane permeable analog of cAMP) for $60 \mathrm{~min}$ prior to and throughout the stimulus period, did not alter resting release of either peptide (hatched columns, Fig. 4), but caused an approximate twofold enhancement of the release evoked by $100 \mathrm{~nm}$ bradykinin (Fig. 4). The bradykinin-evoked release of iSP was elevated from $45 \pm 3 \mathrm{fmol} / \mathrm{well} / 10 \mathrm{~min}$ in cultures not treated with 8 -bromo cAMP to $112 \pm 16 \mathrm{fmol} / \mathrm{well} / 10 \mathrm{~min}(n$ $=15$ wells) after the cAMP analog. In a similar manner, iCGRP release was augmented from $91 \pm 8$ to $163 \pm 18 \mathrm{fmol} / \mathrm{well} / 10$ $\min$.

Exposing the cultures to a lower concentration of 8-bromocAMP $(10 \mu \mathrm{M})$ did not alter either the resting or bradykininevoked release of either peptide. When sensory neurons were exposed to $100 \mathrm{~nm}$ bradykinin alone, release of iSP was $51 \pm$ $4 \mathrm{fmol} / \mathrm{well} / 10 \mathrm{~min}$ and $\mathrm{iCGRP}$ release was $124 \pm 7 \mathrm{fmol} / \mathrm{well} /$ $10 \mathrm{~min}$, whereas the bradykinin-stimulated release of iSP and iCGRP in the presence of $10 \mu \mathrm{M}$ 8-bromo-cAMP was $54 \pm 4$ and $89 \pm 7 \mathrm{fmol} /$ well/10 $\mathrm{min}$ for iSP and iCGRP, respectively.
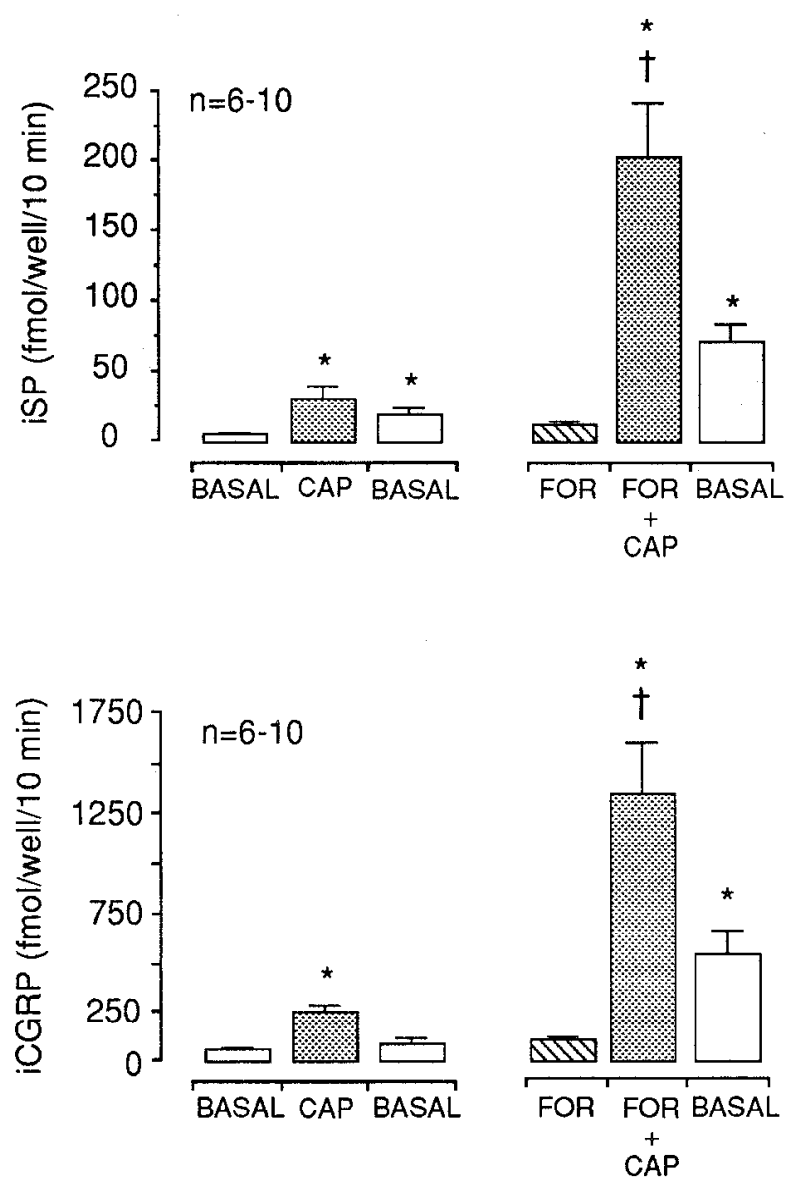

Figure 3. Forskolin augments capsaicin-stimulated release of iSP and iCGRP from rat sensory neurons. The ordinates represent the amount of iSP (upper panel) or iCGRP (lower panel) released expressed in fmol/well/10 min incubation period. Each column represents the mean \pm SEM of the amount of peptide released from 6-10 wells. Open columns represent the release of peptide when cells werc cxposed to HEPES buffer alone (BASAL); hatched columns represent release when cells were exposed to $1 \mu \mathrm{M}$ forskolin $(F O R)$, and shaded columns indicate the release elicited by $50 \mathrm{~nm}$ capsaicin $(C A P)$. In the panels on the right, cells were treated with $1 \mu \mathrm{M}$ forskolin for $10 \mathrm{~min}$ prior to and throughout the capsaicin stimulation. An asterisk indicates a statistically significant difference from the initial basal release. A $\dagger$ indicates significant differences between capsaicin-evoked release in the absence and presence of forskolin. Both differences were determined by an analysis of variance and Fisher's LSD $( \pm<0.05)$.

We also examined the effects of cholera toxin treatment on peptide release. For these studies, sensory neurons were exposed to $1.5 \mathrm{mg}$ of cholera toxin for $16 \mathrm{hr}$; a treatment that ADPribosylates in excess of $95 \%$ of Gs (data not shown). As with the other manipulations to increase intracellular cAMP content, exposing sensory neurons to cholera toxin augmented the bradykinin-stimulated release of iSP and iCGRP (Fig. 5). The bradykinin-evoked release of iSP and iCGRP from sensory neurons not exposed to cholera toxin was $61 \pm 7$ and $134 \pm 10 \mathrm{fmol} /$ well/10 min (left panels, Fig. 5). In cultures pretreated with cholera toxin release stimulated by bradykinin was increased approximately twofold to $120 \pm 3 \mathrm{fmol} / \mathrm{well} / 10 \mathrm{~min}$ for iSP and to $293 \pm 21 \mathrm{fmol} / \mathrm{well} / 10 \mathrm{~min}$ for iCGRP. Resting or basal release of the peptides was not affected by cholera toxin in the 10 min incubation prior to bradykinin exposure (hatched columns, Fig. 5). Taken together, these data demonstrate that increasing 

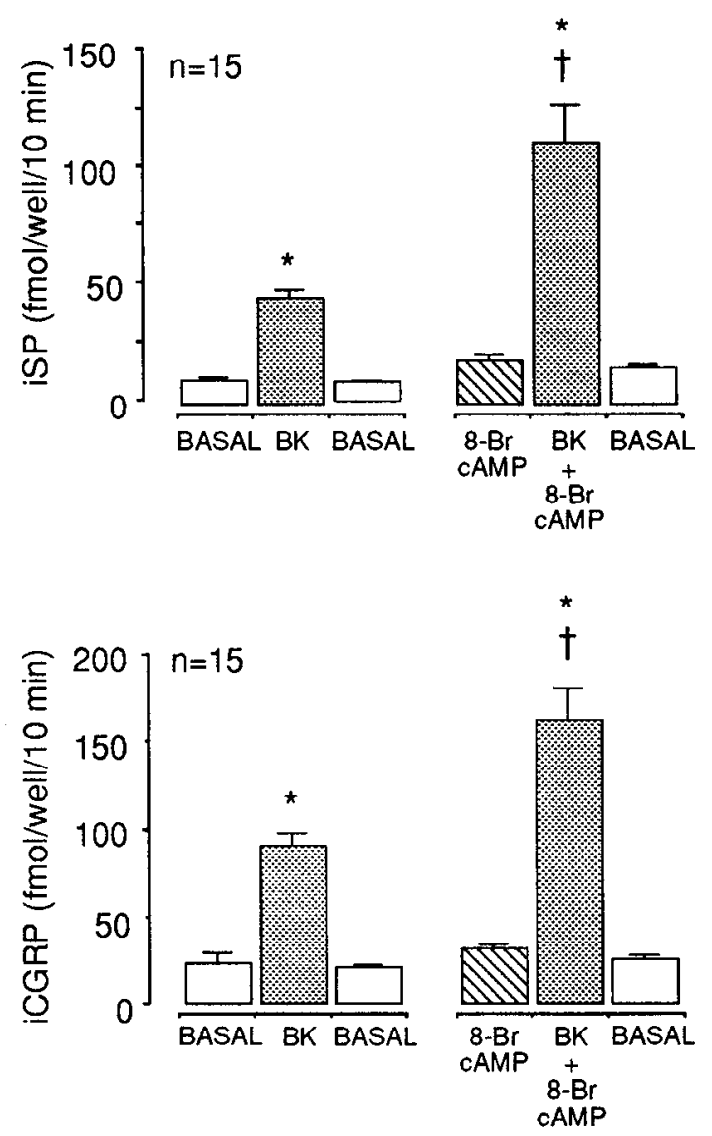

Figure 4. Bradykinin-stimulated release of iSP and iCGRP is enhanced by treatment with 8-bromo cAMP. The columns represent the mean \pm SEM of the amount of iSP (upper panel) or iCGRP (lower panel) released in $\mathrm{fmol} / \mathrm{well} / 10 \mathrm{~min}$ incubation. Open columns show release when cells are exposed to HEPES buffer alone (BASAL; resting release), hatched columns represent peptide release after treatment for 50 min with $100 \mu \mathrm{M}$ 8-bromo cAMP ( 8 -Br cAMP), and shaded columns release stimulated by $100 \mathrm{nM}$ bradykinin $(B K)$ alone (left panels) or in cultures pretreated for $1 \mathrm{hr}$ with $100 \mu \mathrm{M} 8$-bromo cAMP (right panels). An asterisk indicates a statistically significant difference from the initial basal release. $\mathrm{A} \dagger$ indicates significant differences between bradykininevoked release in the absence and presence of 8-bromo cAMP. Both differences were determined by an analysis of variance and Fisher's $\operatorname{LSD}(p<0.05)$.

intracellular levels of cAMP causes a facilitation of stimulusevoked release of neuropeptides from rat sensory neurons.

\section{Inhibition of adenylyl cyclase abolishes prostaglandin- enhanced release of $i C G R P$}

To establish a causal relationship between the elevation of intracellular cAMP and prostaglandin-induced facilitation of peptide release, we determined the effect of pretreating sensory neurons with the adenylyl cyclase inhibitor, 9-tetrahydro-2-furyl adenine (THFA; Goldsmith and Abrams, 1991) on peptide release. Cultures were treated with $5 \mathrm{~mm}$ THFA for $60 \mathrm{~min}$ prior to the beginning of the release experiment and treatment continued throughout exposure to either $100 \mathrm{~nm}$ bradykinin or $50 \mathrm{nM}$ capsaicin. As can be seen in Figure 6, exposing the neuronal cultures to $5 \mathrm{~mm}$ THFA abolished the increase in icAMP levels caused by either $100 \mathrm{nM} \mathrm{PGE}_{2}$ or 1 IIM $\mathrm{CPGI}_{2}$. As in previous experiments, when cultures were exposed to $2 \mathrm{mM}$ IBMX then treated with prostaglandins, there was an approximate twofold increase in icAMP content. Basal levels of icAMP were $6.6 \pm$
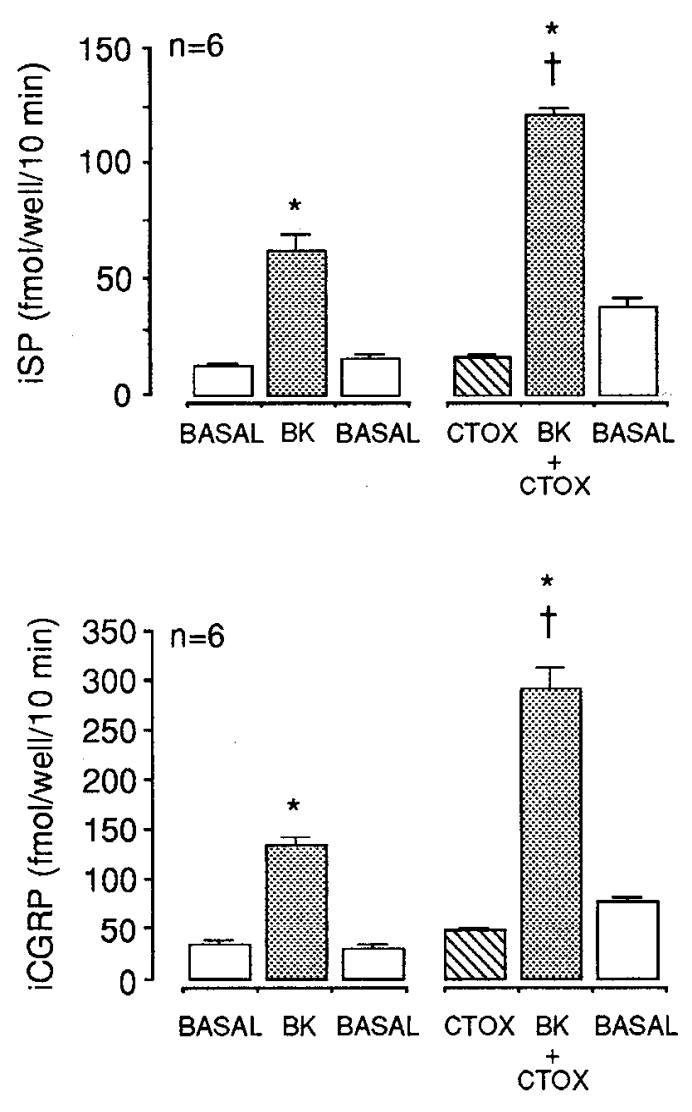

Figure 5. Bradykinin-stimulated release of iSP and iCGRP is enhanced by treatment with cholera toxin. The columns represent the mean \pm SEM of the amount of iSP (upper panel) or iCGRP (lower panel) released in $\mathrm{fmol} / \mathrm{well} / 10 \mathrm{~min}$ incubation. Open columns show release when cells are exposed to HEPES buffer (BASAL; resting release), hatched columns represent peptide release after treatment with $1.5 \mathrm{mg}$ cholera toxin (CTOX), and shaded columns release stimulated by $100 \mathrm{nM}$ bradykinin $(B K)$ alone (left panels) or in cultures pretreated for $16 \mathrm{hr}$ with $1.5 \mathrm{mg}$ cholera toxin (right panels). An asterisk indicates a statistically significant difference from the initial basal release. A $\dagger$ indicates significant differences between bradykinin-evoked release in the absence and presence of cholera toxin. Both differences were determined by an analysis of variance and Fisher's LSD $(p<0.05)$.

$0.4 \mathrm{pmol} /$ well of neurons, whereas $100 \mathrm{nIM} \mathrm{PGE}_{2}$ or $1 \mathrm{nM} \mathrm{CPGI}_{2}$ increased levels to $11.1 \pm 0.8$ or $11.2 \pm 2.0 \mathrm{pmol} / \mathrm{well}$, respectively. When cultures were pretreated with $5 \mathrm{~mm}$ THFA, icAMP levels were $7.0 \pm 0.8$ after $\mathrm{PGE}_{2}$ and $6.0 \pm 1.0$ after $\mathrm{CPGI}_{2}$.

Because 5 mM THFA abolished the prostaglandin-induced increase in icAMP content, we studied whether this inhibitor of adenylyl cyclase would affect the ability of $\mathrm{PGE}_{2}$ or $\mathrm{CPGI}_{2}$ to enhance the release of iCGRP evoked by bradykinin or capsaicin. In these experiments, we only examined the effects on iCGRP release because $5 \mathrm{~mm}$ THFA interfered with the SP radioimmunoassay. As shown in Figure 7A, exposing sensory neurons in culture to $100 \mathrm{nM}$ bradykinin increases the release of iCGRP from a basal level of $149 \pm 25$ to $415 \pm 83 \mathrm{fmol} / \mathrm{well} /$ $10 \mathrm{~min}$. Pretreatment with $100 \mathrm{nM} \mathrm{PGE}_{2}$ for 20 min significantly enhanced the bradykinin-stimulated release 1.4-fold to a value of $600 \pm 82 \mathrm{fmol} /$ well $/ 10 \mathrm{~min}(n=8$ wells $)$. When cells were treated with $5 \mathrm{mM}$ THFA, the $\mathrm{PGE}_{2}$-mediated enhancement of stimulated release was abolished $(317 \pm 53 \mathrm{fmol} /$ well $10 \mathrm{~min})$. The adenylyl cyclase inhibitor did not alter the resting release 


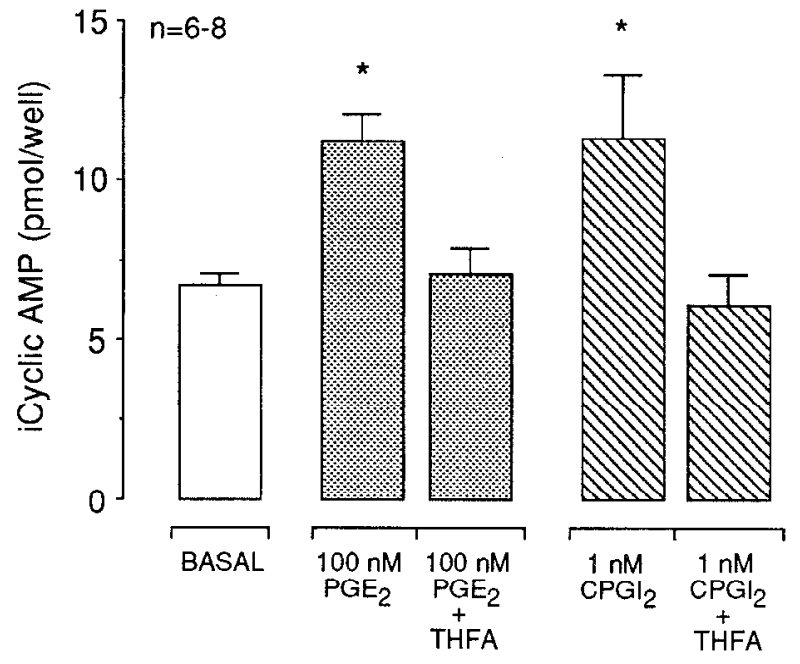

Figure 6. 9-Tetrahydro-2-furyl adenine (THFA) inhibits the formations of icAMP induced by prostaglandins in sensory neuronal cultures. The columns represent the mean \pm SEM of the amount of icAMP extracted from individual sensory neuron cultures in $\mathrm{pmol} / \mathrm{well}$. The open column shows icAMP formed when cells are exposed to HEPES buffer containing $2 \mathrm{mM}$ IBMX without additional drug treatinent ( $B A S$ $A L)$. The shaded columns and the hatched columns represent cells treated with buffer containing IBMX and either $100 \mathrm{nM} \mathrm{PGE}_{2}$ for $20 \mathrm{~min}$ or $1 \mathrm{nM} \mathrm{CPGI}$ for $30 \mathrm{~min}$ in the absence or presence of pretreatment with $5 \mathrm{~mm}$ THFA for $60 \mathrm{~min}$ prior to the addition of prostanoids. An asterisk indicates significant differences from controls determined by analysis of variance and determined by an analysis of variance and Fisher's LSD $(p<0.05)$.

of iCGRP; however, THFA significantly attenuated the bradykinin stimulated release to $222 \pm 30 \mathrm{fmol} / \mathrm{well} / 10 \mathrm{~min}$.

9-Tetrahydro-2-furyl adenine also abolished the $\mathrm{CPGI}_{2}$-mediated enhancement of capsaicin-stimulated release (Fig. $7 B$ ). Exposing the neurons to $50 \mathrm{~nm}$ capsaicin caused a fourfold increase in iCGRP relcase from a resting level of $128 \pm 12 \mathrm{fmol} /$ well $/ 10 \mathrm{~min}$ to $542 \pm 96 \mathrm{fmol} / \mathrm{well} / 10 \mathrm{~min}$. When cultures were pretreated with $1 \mathrm{nM} \mathrm{CPGI}_{2}$ for $30 \mathrm{~min}$, the capsaicin-stimulated release was facilitated twofold to $1009 \pm 210 \mathrm{fmol} / \mathrm{well} / 10 \mathrm{~min}$. In sensory neuronal cultures treated with $5 \mathrm{~mm}$ THFA, there was no significant inhibition of the capsaicin-evoked release of iCGRP, but the $\mathrm{CPGI}_{2}$-mediated facilitation of peptide release was abolished. Release in the presence of $\mathrm{CPGI}_{2}$, capsaicin, and THFA was reduced to $535 \pm 118 \mathrm{fmol} / \mathrm{well} / 10 \mathrm{~min}$. These results demonstrate that increasing adenylyl cyclase activity and the resulting increase in cAMP are necessary for prostaglandininduced facilitation of peptide release.

\section{Discussion}

The findings in this study establish that the cAMP transduction cascade mediates the prostaglandin-induced augmentation of peptide release from rat sensory ncurons. Nanomolar concentrations of either $\mathrm{PGE}_{2}$ or $\mathrm{CPGI}_{2}$ significantly increase the content of icAMP in neuronal cultures. This profile of prostanoid action on icAMP parallels the effects of these autocoids on peptide release from isolated sensory neurons. Indeed, we have previously demonstrated that the same concentrations of $\mathrm{PGE}_{2}$ or $\mathrm{CPGI}_{2}$ that increase icAMP content enhance iSP and iCGRP release evoked by either bradykinin, capsaicin, or high extracellular potassium (Hingtgen and Vasko, 1994a; Vasko et al., 1994). In contrast, $\mathrm{PGF}_{2 \alpha}$ does not facilitate evoked release of neuropeptides nor does it elevate the content of icAMP.
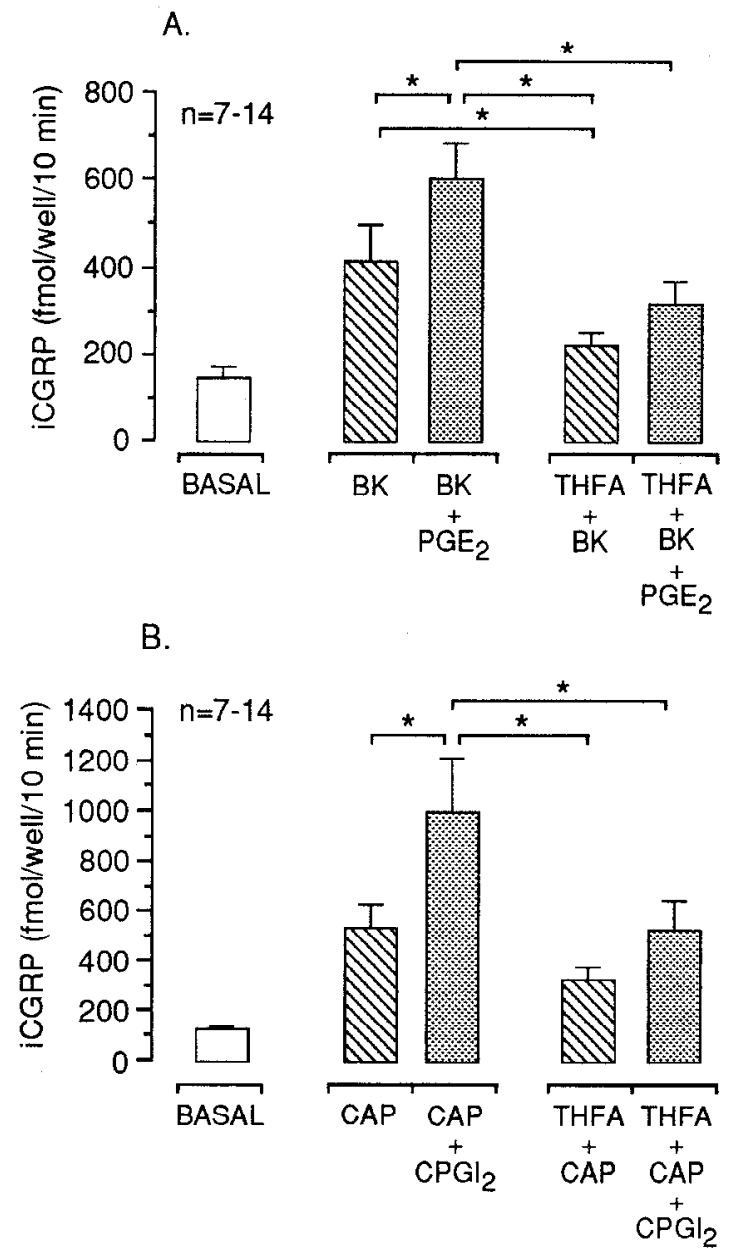

Figure 7. 9-Telrahydro-2-furyl adenine (THFA) inlibits prosiaglandin-induced enhancement of stimulus-evoked neuropeptide release. The ordinates represent the amount of iCGRP release expressed in fmol per well for each $10 \mathrm{~min}$ incubation period. Each column represents the mean \pm SEM of the amount of peptide released from 7-14 wells. Open columns represent the release of peptide when cells were exposed to HEPES buffer alone (BASAL); hatched columns represent release when cells were exposed to $100 \mathrm{nM}$ bradykinin ( $B K$; upper panel) or $50 \mathrm{nM}$ capsaicin (CAP; lower panel), and shaded columns indicate the release elicited by the stimuli after pretreatment with either $100 \mathrm{nM} \mathrm{PGE}_{2}$ (upper panel) or $1 \mathrm{nM} \mathrm{CPGI}$ (lower panel). Where indicated, cells were exposed to $5 \mathrm{~mm}$ THF $\Lambda 60 \mathrm{~min}$ prior to and throughout the stimulus exposure. An asterisk indicates a statistically significant difference between treatments determined by an analysis of variance and BonferroniDunn all means test $(p<0.05)$.

Increasing the content of cAMP in the neuronal cultures also enhances the evoked release of iSP and iCGRP in a manner analogous to that observed with prostaglandins (Hingtgen and Vasko, 1994a; Vasko et al., 1994). We used three different agents to increase cAMP in the cultures; forskolin, 8-bromo cAMP, and cholera toxin. Forskolin directly activates adenylyl cyclase (Seamon and Daly, 1983), whereas 8-bromo cAMP is a membrane permeable and stable analog of cAMP (Miller et al., 1975), and cholera toxin activates the guanine nucleotide binding protein, Gs (Cassel and Selinger, 1977). Treating sensory neurons with any of these agents produces qualitatively similar effects on peptide release. In all instances, the activation of the cAMP transduction cascade sensitizes the sensory neurons, thereby augmenting release evoked by stimulating agents without significantly altering resting release. Because these agents increase the 
intracellular content of cAMP through separate mechanisms, it is highly unlikely that the facilitation of peptide release is the result of a nonspecific effect of any agent not related to elevation of cAMP.

Our results demonstrating that prostaglandin-sensitization is attenuated by inhibiting the activity of adenylyl cyclase establishes a cause-effect relationship between actions of prostaglandins to increase cAMP levels and to enhance sensory neuron activity. Pretreating the sensory neurons in culture with the adenylyl cyclase inhibitor, THFA, abolishes the $\mathrm{PGE}_{2}$ and $\mathrm{CPGI}_{2}-$ induced increase in icAMP content. The same concentration of THFA also significantly reduces the prostaglandin-mediated actions on the evoked release of iCGRP caused by two stimulating agents, bradykinin and capsaicin. These results, taken with the other findings discussed above, strongly support the conclusion that prostaglandins augment release through activation of the cAMP second-messenger system.

Interestingly, exposing neuronal cultures to THFA not only attenuates the actions of prostaglandins but also significantly reduces the bradykinin-evoked release of iCGRP. This finding suggests that a component of the bradykinin-evoked release is mediated by $\mathrm{c} \Lambda \mathrm{MP}$. The actions of bradykinin on sensory neurons are thought to be mediated by activation of protein kinase $\mathrm{C}$ (Thayer et al., 1988; Burgess et al., 1989). Thus, it is possible that activation of $\mathrm{PKC}$ by bradykinin results in phosphorylation of isoforms of adenylyl cyclase, thereby increasing the production of cAMP. There is precedence for this type of "cross-talk" between second messengers. Phorbol esters activate PKC and this results in phosphorylation of various isoforms of adenylyl cyclase, thus increasing intracellular cAMP (Bell et al., 1985; Sibley et al., 1986; Jacohowitz et al., 1993). Whether the isoenzymes of adenylyl cyclase that are substrates for PKC are present in sensory neurons is yet to be determined.

It also is possible that bradykinin is increasing the production of endogenous prostaglandins in the neuronal cultures and these autocoids produce an increase in icAMP in sensory neurons and thus enhance release. Three lines of evidence support this possibility. First, rat sensory neurons in culture are capable of synthesizing prostaglandins, predominately, $\mathrm{PGE}_{2}$ (Vasko et al., 1994). Second, the bradykinin-evoked release of iSP and iCGRP for isolated sensory neurons are partially blocked by indomethacin, an inhibitor of PG synthesis, in a manner analogous to the effects of l'HFA (Vasko et al., 1994). Furthermore, other studies have shown that the stimulatory actions of bradykinin on sensory neurons are reduced in the presence of indomethacin (Griesbacher and Lembeck, 1987; Dray et al., 1992; Rueff and Dray, 1993). Finally, bradykinin stimulates the release of arachidonic acid from sensory neurons (Gammon et al., 1989) and increases the formation of prostaglandins in a number of tissues (McGiff et al., 1972; Lembeck et al., 1976; Allen et al., 1992).

Our observation that cAMP mediates the facilitation of transmitter release in sensory neurons is consistent with findings in other neuronal preparations. For example, Kandel and co-workers showed that injection of cAMP or of the catalytic subunit of protein kinase A (PKA) into the sensory neuron of Aplysia, increases excitatory postsynaptic potentials (Castellucci et al., 1980; Klein and Kandel, 1980). In addition, Andreeva and Rang (1993) observed a facilitation of electrically stimulated release of CGRP from rat spinal cord slices after exposure to forskolin or a phosphodiesterase inhibitor.

The current results also substantiate the work of Ferreria and Nakamura (1979) and Taiwo and Levine (1991) that cAMP me- diates hyperalgesia and the sensitizing action of prostaglandins on paw withdrawal in response to a noxious stimulus. Indeed, an increase in the release of the neuropeptides SP and CGRP could be one mechanism to account for prostaglandin and cAMP-induced hyperalgesia. The current results, however, disagree with the conclusions of Kumazawa et al. (1993) that a decrease in intracellular cAMP, rather than an increase, mediates prostaglandin sensitization of bradykinin activation of sensory neurons. They demonstrated that M\&B28767, an agonist at the $\mathrm{EP}_{3}$ receptor, mimics $\mathrm{PGE}_{2}$-induced enhancement of bradykininevoked discharges of the canine testis-spermatic nerve. This prostaglandin receptor is believed to be coupled to the G-protein, Gi, which inhibits adenylyl cyclasc activity (Smith, 1992). They also observed that butaprost, an agonist at the $\mathrm{EP}_{2}$ receptor (a receptor reported to be positively coupled to adenylyl cyclase activity (Honda et al., 1993), does not enhance the bradykininevoked response. This discrepancy between their conclusions and our work might be explained by the recent discovery of different subtypes of $\mathrm{EP}_{3}$ receptors, that do not differ in agonist affinities, but couple to different G-proteins, including $\mathrm{Gi}$ and Gs (Namba et al., 1993). Thus, drug-induced activation of the $\mathrm{EP}_{3}$ receptors on sensory neurons could increase or decrease the production of cAMP, depending on the relative affinity of receptor agonists and antagonists for the $\mathrm{EP}_{3}$ receptor isoforms.

It is likely that the prostaglandin activation of the adenylyl cyclase and the subsequent increase in cAMP will result in an increase in the phosphorylation of various proteins by PKA. Indeed, we have recently demonstrated that treating sensory neurons with the phosphatase inhibitor, okadaic acid, can sensitize these neurons to release evoked by bradykinin, capsaicin, or high extracellular potassium (Hingtgen and Vasko, 1994b). This effect of okadaic acid on release is similar to that observed with $\mathrm{PGE}_{2}$ and $\mathrm{CPGI}_{2}$ and with an increase in intracellular icAMP, and suggests that enhanced protein phosphorylation may be a component of prostaglandin-induced sensitization.

There are a number of substrates of protein phosphorylation that could account for the increase in peptide release. One possibility is that PKA phosphorylates synaptic proteins that could alter the interaction of the vesicle with the cell membrane, thus allowing more peptide to be available for release upon stimulation. Although phosphorylation of synaptic proteins by PKA has not been demonstrated in mammalian sensory neurons, it has been observed in other neuronal systems (Levitan, 1988; Greengard et al., 1993). It is also possible that PKA directly phosphorylates ion channels, increasing the excitability of sensory neurons. Indeed, a number of studies have shown that both prostaglandins and cAMP facilitate the bradykinin and capsaicin-induced excitation of sensory neurons (Handwerker, 1976; Martin et al., 1987; Dray et al., 1992; Rueff and Dray, 1993; Nicol and Cui, 1994). Furthermore, using patch-clamp techniques to record from isolated sensory neurons, Cui and Nicol (1994) recently demonstrated that $\mathrm{PGE}_{2}$ pretreatment increases the number of action potential elicited by bradykinin and that this action is blocked by inhibition of PKA activity. Thus, the prostaglandin-induced increase in peptide release could result from increased excitability of sensory neurons presumably by affecting activity of ion channels. Indeed, $\mathrm{PGE}_{2}$ and $\mathrm{PGD}_{2}$ but not $\mathrm{PGF}_{2 \alpha}$, reduce the calcium-induced afterhyperpolarization of rabbit visceral sensory neurons (Weinreich and Wonderlin, 1987). This afterhyperpolarization appears to be mediated by a potassium channel, and the effects of prostaglandins are mimicked by forskolin. Similar results were reported by Grega and 
MacDonald (1987) in mouse sensory neurons grown in culture. In addition, prostaglandins enhance calcium conductance in avian sensory neurons (Nicol et al., 1992), brain synaptosomes (Kandasamy and Hunt, 1990), and guinea-pig ventricular heart cells (Alloatti et al., 1991).

The results presented here clearly demonstrate that prostaglandin-induced facilitation of iSP and iCGRP release from sensory neurons is mediated by the adenylyl cyclase/cAMP transduction cascade. It remains to be determined whether specific cellular proteins are phosphorylated by activation of PKA and how this change in posttranslational processing affects neuropeptide release from sensory neurons and the processes of pain signaling and neurogenic inflammation.

\section{References}

Allen AC, Gammon CM, Ousley AH, McCarthy KD, Morell P (1992) Bradykinin stimulates arachidonic acid release through the sequential actions of an sn-1 diacylglycerol lipase and a monoacylglycerol lipase. J Neurochem 58:1130-1139.

Alloatti G, Serazzi L, Levi RC (1991) Prostaglandin $\mathrm{I}_{2}\left(\mathrm{PGI}_{2}\right)$ enhances calcium currents in guinea-pig ventricular heart cells. J Mol Cell Cardiol 23:851-860.

Andreeva L, Rang HP (1993) Effect of bradykinin and prostaglandins on the release of calcitonin gene-related peptide-like immunoreactivity from the rat spinal cord in vitro. Br J Pharmacol 108:185-190.

Baccaglini PI, Hogan PG (1983) Some rat sensory neurons in culture express characteristics of differentiated pain sensory cells. Proc Natl Acad Sci USA 80:594-598.

Bell JD, Buxton ILO, Brunton LL (1985) Enhancement of adenylate cyclase activity in S49 lymphoma cells by phorbol esters. J Biol Chem 260:2625-2628

Burgess GM, Mullaney I, McNeill M, Dunn PM, Rang HP (1989) Second messengers involved in the mechanism of action of bradykinin in sensory neurons in culture. $\mathbf{J}$ Neurosci 9:3314-3325.

Cassel, D, Selinger, Z (1977) Mechanism of adenylate cyclase activation by cholera toxin: inhibition of GTP hydrolysis at the regulatory site. Proc Nall Acad Sci USA 74:3301-3311.

Castellucci VF, Kandel ER, Schwartz JH, Wilson FD, Nairn AC, Greengard P (1980) Intracellular injection of the catalytic subunit of cyclic AMP- dependent protein kinase stimulates facilitation of transmitter release underlying behavioral sensitization in Aplysia. Proc Natl Acad Sci USA 77:7492-7496.

Cuello AC (1987) Peptides as neuromodulators in primary sensory neurons. Neuropharmacology 26:971-979.

Cui M, Nicol GD (1994) Cyclic AMP mediates the prostaglandin $\mathrm{F}_{2-}$ induced potentiation of bradykinin excitation in rat sensory neurons. Neuroscience, in press.

Dray $\Lambda$, Patel I $\Lambda$, Perkins MN, Rueff $\Lambda$ (1992) Bradykinin-induced activation of nociceptors: receptor and mechanistic studies on the neonatal rat spinal cord-tail preparation in vitro. $\mathrm{Br} \mathrm{J}$ Pharmacol 107 $1129-1134$.

Ferreira SH (1972) Prostaglandins, aspirin-like drugs and analgesia. Nature New Biol 240:200-203.

Ferreira SH, Nakamura M (1979) Prostaglandin hyperalgesia, a cAMP/ $\mathrm{Ca}^{2+}$ dependent process. Prostaglandins 18:179-190.

Ferreira SH, Nakamura M, de Abreu Castro MS (1978) The hyperalgesic effects of prostacyclin and prostaglandin $\mathrm{E}_{2}$. Prostaglandins 16 : $31-37$.

Franco-Cereceda A (1989) Prostaglandins and CGRP release from cardiac sensory nerves. Naunyn Scmiedebergs Arch Pharmacol 340: $180-184$

Gammon CM, Allen AC, Morell P (1989) Bradykinin stimulates phosphoinositide hydrolysis and mobilization of arachidonic acid in dorsal root ganglia neurons. J Neurochem 53:95-101.

Geppetti P, Del Bianco E, Tramontana M, Vigano T, Folco GC, Maggi CA, Manzini S, Fanciullacci M (1991) Arachidonic acid and bradykinin share a common pathway to release neuropeptide from capsaicin-sensitive sensory nerve fibers of the guinea pig heart. J Pharmacol Exp Ther 259:759-765.

Goldsmith BA, Abrams TW (1991) Reversal of synaptic depression by serotonin at Aplysia sensory neuron synapses involves activation of adenylyl cyclase. Proc Natl Acad Sci USA 88:9021-9025.
Greengard P, Valtorta F, Czernik AJ, Benfenati F (1993) Synaptic vesicle phosphoproteins and regulation of synaptic function. Science 259:780-785.

Grega DS, Macdonald RL (1987) Activators of adenylate cyclase and cyclic AMP prolong calcium-dependent action potentials of mouse sensory neurons in culture by reducing a voltage-dependent potassium conductance. J Neurosci 7:700-707.

Griesbacher T, Lembeck F (1987) Effect of bradykinin antagonists on bradykinin-induced plasma extravasation, venoconstriction, prostaglandin $\mathrm{E}_{2}$ release, nociceptor stimulation and contraction of the iris sphincter muscle in the rabbit. Br J Pharmacol 92:333-340.

Handwerker HO (1976) Influences of algogenic substances and prostaglandins on the discharges of unmyelinated cutaneous nerve fibers identified as nociceptors. In: Advances in pain research and therapy, Vol 1 (Bonica JJ, Albe-Fessard D, eds), pp 41-45. New York: Raven.

Hingtgen CM, Vasko MR (1992) Carba prostacyclin potentiates capsaicin- stimulated release of neuropeptides from rat sensory neurons in culture. Soc Neurosci Abstr 18:691.

Hingtgen CM, Vasko MR (1994a) Prostacyclin enhances the evoked release of substance $P$ and calcitonin gene-related peptide from rat sensory neurons. Brain Res 655:51-60.

Hingtgen CM, Vasko MR (1994b) The phosphatase inhibitor, okadaic acid increases peptide release from rat sensory neurons in culture. Neurosci Lett 178:135-138.

Holzer P (1991) Capsaicin: cellular targets, mechanisms of action, and selectivity for thin sensory neurons. Pharmacol Rev 43:143 200.

Honda A, Sugimoto Y, Namba T, Watabe A, Irie A, Negishi M, Narumiya S, Ichikawa A (1993) Cloning and expression of a cDNA for mouse prostaglandin $\mathrm{E}$ receptor $\mathrm{EP}_{2}$ subtype. J Biol Chem 268:77597762 .

Jacobowitz O, Chen J, Premont RT, Iyengar R (1993) Stimulation of specific types of Gs-stimulated adenylyl cyclases by phorbol ester treatment. J Biol Chem 268:3829-3832.

Jaschonek K, Faul C, Schmidt H, Renn W (1988) Desensitization of platelets to iloprost. Loss of specific binding sites and heterologous desensitization of adenylate cyclase. Eur J Pharmacol 147:187-196.

Kandasamy SB, Hunt WA (1990) Arachidonic acid and prostaglandins enhance potassium-stimulated calcium influx into rat brain synaptosomes. Neuropharmacology 29:825-829.

Klein M, Kandel ER (1980) Mechanism of calcium current modulation underlying presynaptic facilitation and behavioral sensitization in Aplysia. Proc Natl Acad Sci USA 77:6912-6916.

Kumazawa T, Mizumura K, Koda $\mathrm{H}$ (1993) Involvement of $\mathrm{EP}_{3}$ subtype of prostaglandin $\mathrm{E}$ receptors in $\mathrm{PGE}_{2}$-induced enhancement of the bradykinin response of nociceptors. Brain Res 632:321-324.

Kuraishi Y, Nanayama T, Hiroshi O, Minami M, Satoh M (1988) Antinociception induced in rats by intrathecal administration of antiserum against calcitonin genc-rclated peptidc. Ncurosci Lett 92:325329.

Laurenza L, Sutkowski EM, Seamon KB (1989) Forskolin: a specific stimulator of adenylyl cyclase or a diterpene with multiple sites of action. Trends Pharmacol Sci 10:442-447.

Lembeck F, Popper H, Juan H (1976) Release of prostaglandins by bradykinin as an intrinsic mechanism of its algesic effect. Naunyn Schmiedebergs Arch Pharmacol 294:69-73.

Levitan I B (1988) Phosphorylation of ion channels. J Membr Biol 87: 177-190.

Martin HA, Basbaum AI, Kwiat GC, Goetzl EJ, Levine JD (1987) Leukotriene and prostaglandin sensitization of cutaneous high-threshold C- and A-Delta mechanonociceptors in the hairy skin of rat hindlimbs. Neuroscience 22:651-659.

McGiff JC, Terragno NA, Malik KU, Lonigro AJ (1972) Release of prostaglandin E-like substance from canine kidney by bradykinin. Circulation Res 31:36-43.

Mense S (1981) Sensitization of group IV muscle receptors to bradykinin by 5-hydroxytryptamine and prostaglandin $\mathrm{E}_{2}$. Brain Res 225: 95-105.

Miller JP, Beck AH, Simon LN, Meyer RB (1975) Induction of hepatic tyrosine aminotransferase in vivo by derivatives of cyclic adenosine $3^{\prime}: 5^{\prime}$-monophosphate. J Biol Chem 250:426-431.

Namba T, Sugimoto Y, Negishi M, Irie A, Ushikubi F, Kakizuka A, Ito S, Ichikawa A, Narumiya S (1993) Alternative splicing of C-terminal tail of prostaglandin $\mathrm{E}$ receptor subtype $\mathrm{EP}_{3}$ determines G-protein specificity. Nature 365:166-170. 
Nicol GD, Cui M (1994) Prostaglandin $E_{2}$ enhances bradykinin activation of embryonic rat sensory neurons. $J$ Physiol (Lond), in press.

Nicol GD, Klingberg DK, Vasko MR (1992) Prostaglandin $E_{2}$ increases calcium conductance and stimulates release of substance $P$ in avian sensory neurons. J Neurosci 12:1917-1927.

Pang IH, Vasko MR (1986) Morphine and norepinephrine but not 5-hydroxytryptamine and gamma-aminobutyric acid inhibit the potassium-stimulated release of substance $\mathrm{P}$ from rat spinal cord slices. Brain Res 376:268-279.

Payan DG (1989) Neuropeptides and inflammation: the role of substance P. Annu Rev Med 40:341-352.

Rueff A, Dray A (1993) Sensitization of peripheral afferent fibers in the in vitro nconatal rat spinal cord-tail by bradykinin and prostaglandins. Neuroscience 54:527-535.

Schaible H-G, Schmidt RF (1988) Excitation and sensitization of fine articular afferents from cat's knee joint by prostaglandin $\mathrm{E}_{2}$. J Physiol (Lond) 403:91-104.

Seamon KB, Daly JW (1983) Forskolin, cyclic AMP and cellular physiology. Trends Pharmacol Sci 6:120-123.

Sibley DR, Jefts RA, Daniel K, Nambi P, Lefkowitz RJ (1986) Phorbol diester treatment promotes enhanced adenylate cyclase activity in frog erythrocytes. Arch Biochem Biophys 244:373-381.

Smith WL (1992) Prostanoid biosynthesis and mechanism of action. Am J Physiol 263:F181-F191.

Smith WL, Watanabe T, Umegaki K, Sonnenburg WK (1987) General biochemical mechanism for prostaglandin actions: direct coupling of prostanoid receptors to guanine nucleotide regulatory proteins. Adv Prostaglandin Thromboxame Leukotreine Res 17:463-466.

Taiwo YO, Levine JD (1986) Indomethacin blocks central nociceptive effects of $\mathrm{PGF}_{2 \alpha}$. Brain Res 373:81-84.

Taiwo YO, Levine JD (1991) Further confirmation of the role of adenyl cyclase and of cAMP-dependent protein kinase in primary afferent hyperalgesia. Neuroscience 44:131-135.

Taiwo YO, Goetzl EJ, Levine JD (1987) Hyperalgesia onset latency suggests a hierarchy of action. Brain Res 423:333-337.

Taiwo YO, Bjerknes IJK, Goetzl EJ, Levine JD (1989) Mediation of primary afferent peripheral hyperalgesia by the cAMP second messenger system. Neuroscience 32:577-580.

Thayer S $\Lambda$, Perney TM, Miller RJ (1988) Regulation of calcium homeostasis in sensory neurons by bradykinin. J Neurosci 8:4089-4097.

Vasko MR, Zirkelbach SL, Waite KJ (1993) Prostaglandins stimulate the release of substance $P$ from rat spinal cord slices. Prog Pharmacol Clin Pharmacol 10:69-89.

Vasko MR, Campbell WB, Waite KJ (1994) Prostaglandin $E_{2}$ enhances bradykinin-stimulated release of neuropeptides from rat sensory neurons in culture. J Neurosci 14:4987-4997.

Waite KJ, Vasko, MR (1992) Prostaglandin $\mathrm{E}_{2}$ and elevation of intracellular cyclic AMP enhance bradykinin-stimulated release of peptides from rat sensory neurons in culture. Soc Neurosci Abstr 18:690.

Weinreich D, Wonderlin WF (1987) Inhibition of calcium-dependent spike after-hyperpolarization increases excitability of rabbit visceral sensory neurons. J Physiol (Lond) 394:415-427. 